\title{
EFFECTS OF EXTRA MASS ON THE PELAGIC BEHAVIOR OF A SEABIRD
}

\author{
Carlos Passos, ${ }^{1}$ Joan Navarro, ${ }^{2,3}$ Alessandro Giudicl, ${ }^{1}$ and Jacob González-Solís ${ }^{1}$ \\ ${ }^{1}$ Departament de Biologia Animal (Vertebrats), Facultat de Biologia, Universitat de Barcelona, \\ Av. Diagonal 645, Barcelona 08028, Spain; and \\ ${ }^{2}$ Department of Conservation Biology, Estación Biológica de Doñana EBD-CSIC, Av. Américo Vespucio s/n, Sevilla 41092, Spain
}

\begin{abstract}
Satellite transmitters and geographic-positioning-system devices often add substantial mass to birds to which they are attached. Studies on the effects of such instruments have focused on indirect measures, whereas the direct influence of extra mass on pelagic behavior is poorly known. We used 2.5-g geolocators to investigate the effect of extra mass on the pelagic behavior of Cory's Shearwaters (Calonectris diomedea) by comparing the traits of a single foraging trip among a group carrying 30 -g weights, a group carrying 60-g weights, and a control group. The weights were attached to the birds' backs using typical techniques for attaching satellite transmitters to seabirds. The extra mass increased the duration of the birds' trips and decreased their foraging efficiency and mass gained at sea. These indirect effects may be related to foraging traits: weighted birds showed a greater search effort than control birds, traveled greater distances, covered a greater foraging area, and increased the maximum foraging range. Furthermore, the time spent on the sea surface at night was greater for weighted than for control groups, which showed that the extra mass also affected activity patterns. Our results underline the need to quantify the effects of monitoring equipment commonly used to study the pelagic behavior of seabirds. We suggest that geolocators can be used to obtain control data on foraging-trip movements and activity patterns. Received 21 December 2008, accepted 20 August 2009.
\end{abstract}

Key words: at-sea activity, Calonectris diomedea, Cory's Shearwater, foraging strategies, geolocators.

\section{Efectos del Peso Suplementario en el Comportamiento Pelágico de un Ave Marina}

RESUMEN.-Los transmisores satelitales y los aparatos con sistemas de posicionamiento geográfico frecuentemente agregan un peso substancial a las aves a las que se los sujetan. Los estudios sobre los efectos de estos instrumentos se han enfocado en medidas indirectas, mientras que la influencia directa del peso extra en el comportamiento pelágico es poco conocida. Empleamos localizadores geográficos de 2.5 g para investigar el efecto del peso extra sobre el comportamiento pelágico de Calonectris diomedea mediante la comparación de los rasgos de un único viaje de forrajeo entre un grupo de aves que portaba pesos de 30 g, un grupo que portaba pesos de $60 \mathrm{~g}$ y un grupo control. Los pesos fueron colocados sobre la espalda de las aves usando las técnicas típicas para sujetar los transmisores satelitales a las aves marinas. El peso extra incrementó la duración de los viajes de las aves y disminuyó su eficiencia de forrajeo y el peso corporal adquirido en el mar. Estos efectos indirectos pueden estar relacionados con los rasgos de forrajeo: las aves con pesos suplementarios mostraron un esfuerzo de búsqueda mayor que las aves control, viajaron distancias más grandes, cubrieron un área de forrajeo mayor e incrementaron el ámbito máximo de forrajeo. Más aún, el tiempo pasado sobre la superficie del mar durante la noche fue mayor para los grupos con peso suplementario que para los grupos control, lo que mostró que el peso suplementario también afectó los patrones de actividad. Nuestros resultados destacan la necesidad de cuantificar los efectos del equipo de monitoreo usado comúnmente para estudiar el comportamiento pelágico de las aves marinas. Sugerimos que los localizadores geográficos pueden ser usados para obtener datos de control de los movimientos de los viajes de forrajeo y de los patrones de actividad.

SEABIRDS ARE HIGHLY mobile and spend much energy and time covering vast distances in migrating and searching for food. Generally, it is difficult to observe them in a pelagic environment, so understanding their behavior at sea remains a major challenge. However, the development of tracking instruments such as satellite transmitters and global-positioning-system (GPS) devices have opened new opportunities to investigate the ecology of seabirds at sea (Burger and Shaffer 2008). These devices have allowed researchers to determine foraging behavior (González-Solís et al. 2002, Weimerskirch et al. 2005, Phalan et al. 2007), investigate the environmental determinants that influence distribution (Hyrenbach et al. 2002, Navarro and González-Solís 2009), and quantify overlap with commercial fisheries (Weimerskirch et al. 1999, Xavier et al. 2004). However, despite the progressively

${ }^{3}$ Address correspondence to this author. E-mail: joan@ebd.csic.es

The Auk, Vol. 127, Number 1, pages 100-107. ISSN 0004-8038, electronic ISSN 1938-4254. @ 2010 by The American Ornithologists' Union. All rights reserved. Please direct all requests for permission to photocopy or reproduce article content through the University of California Press's Rights and Permissions website, http://www.ucpressjournals. com/reprintInfo.asp. DOI: 10.1525/auk.2009.09036 
smaller size of the devices and their great potential for monitoring the pelagic ecology of birds, technical constraints limit their application in some species (Phillips et al. 2003, Söhle 2003) because the mass of the instrument can distort the normal behavior of the birds and compromise the observations.

Most studies have focused on indirect measures of the effects of tracking instruments, for example by monitoring body and meal mass, reproductive success, and the duration of foraging trips (Hamer et al. 2000, Ballard et al. 2001, Phillips et al. 2003, Paredes et al. 2005). Many studies have detected some effects, particularly when the mass of the device exceeded the suggested critical point of $3 \%$ of body mass of the bird (Phillips et al. 2003). However, the direct influence of extra mass on foraging behavior at sea is poorly known because until recently the devices used to track this behavior also added substantial extra mass (2-7\% of body mass) to the birds. In consequence, the effect on distance traveled, area covered during the trip, maximum distance flown from the colony, activity patterns, and flight speed remain essentially unknown.

This gap in our knowledge can now be addressed by the use of geolocation (global location sensing or GLS logging). Geolocators can obtain information on the movements of seabirds by recording light levels during their trips (Hill 1994). Their small size allows them to be attached to a Darvic ring in combination with a weight on the back of the bird, where platform transmitter terminals (PTTs) or GPS devices are usually attached. Therefore, geolocators can be used to evaluate the effects of extra mass on the pelagic behavior of seabirds. Geolocators provide 2 locations per day (local midday and midnight) with a mean accuracy for studies on seabirds that ranges from 186 to $202 \mathrm{~km}$ (Afanasyev 2004, Phillips et al. 2004, Shaffer et al. 2005). Moreover, geolocators can be equipped with a sensor for conductivity to record the time when the bird is resting on the sea surface.

The aim of this study was to investigate the effects of extra mass on the pelagic behavior of Cory's Shearwater (Calonectris diomedea), a medium-size petrel species. We compared the traits of a single foraging trip (distance traveled, area covered, maximum distance flown from the breeding colony, flight speed, and activity pattern) among a group of Cory's Shearwaters carrying 30-g weights ( $\sim 3.8 \%$ of body mass), a group carrying 60 -g weights $(-7.6 \%$ of body mass), and a control group. We chose $30 \mathrm{~g}$ because that is the mass of PTTs (with battery) that are often used on Calonectris spp. (e.g., Magalhães et al. 2008, Navarro and González-Solís 2009). Also, it is around the typical $3 \%$ of body mass, so it is a good simulation of the load imposed by any given device. The 60 -g weights were used to confirm that the effects found in birds carrying $30 \mathrm{-g}$ weights would intensify in the expected direction when the mass was increased. To record the traits of the foraging trip, all control and weighted birds were equipped with 2.5 -g geolocators, which represent only $0.3 \%$ of the body mass. We also recorded the usual indirect measures used to study the effects of extra mass on birds, such as duration of the foraging trip and mass gained at sea.

\section{Methods}

\section{Study Species}

The Cory's Shearwater is a colonial pelagic petrel that breeds mainly on the northeast Atlantic archipelagoes. The species is long-lived and has delayed maturity, high reproductive investment (8 months), long incubation (54 days) and chick-rearing (90 days) periods, 1-egg clutches, and slow postnatal growth. Birds nest in rock crevices, both natural and excavated burrows under rocks or soil. Incubation duties are shared by both sexes and when one partner is incubating the other is foraging. Diet mainly comprises epipelagic and mesopelagic fish and squid (for more details, see Thibault et al. 1997).

\section{Field Work}

We conducted the study in 2007 during the incubation period (June and July) on Gran Canaria $\left(15^{\circ} 47^{\prime} 18^{\prime \prime} \mathrm{N}, 27^{\circ} 50^{\prime} 41^{\prime \prime} \mathrm{E}\right)$ in the Canary Islands, Spain (Fig. 1). Nests were visited daily to record incubation bouts and foraging trips. Each bird in a mating pair was marked with a different color on the head and breast using picric acid, which allowed us to identify the incubating bird without disturbing it on each visit. We measured changes in mass by weighing the females every 3 days until departure on a foraging trip and again when they returned from the trip. Birds were weighed using a Pesola spring balance $( \pm 10 \mathrm{~g})$.

To avoid potential sex-related variability, we used only females in the study. A total of 36 birds were assigned randomly into 3 groups of 12 birds each: control, 30 -g, and 60 -g groups. We attached 30 -g and 60-g flat lead weights, respectively, to the backs of birds in the latter 2 groups, representing an average increase of $3.8 \%$ and $7.6 \%$ of their body mass, respectively (body mass $=788.8$

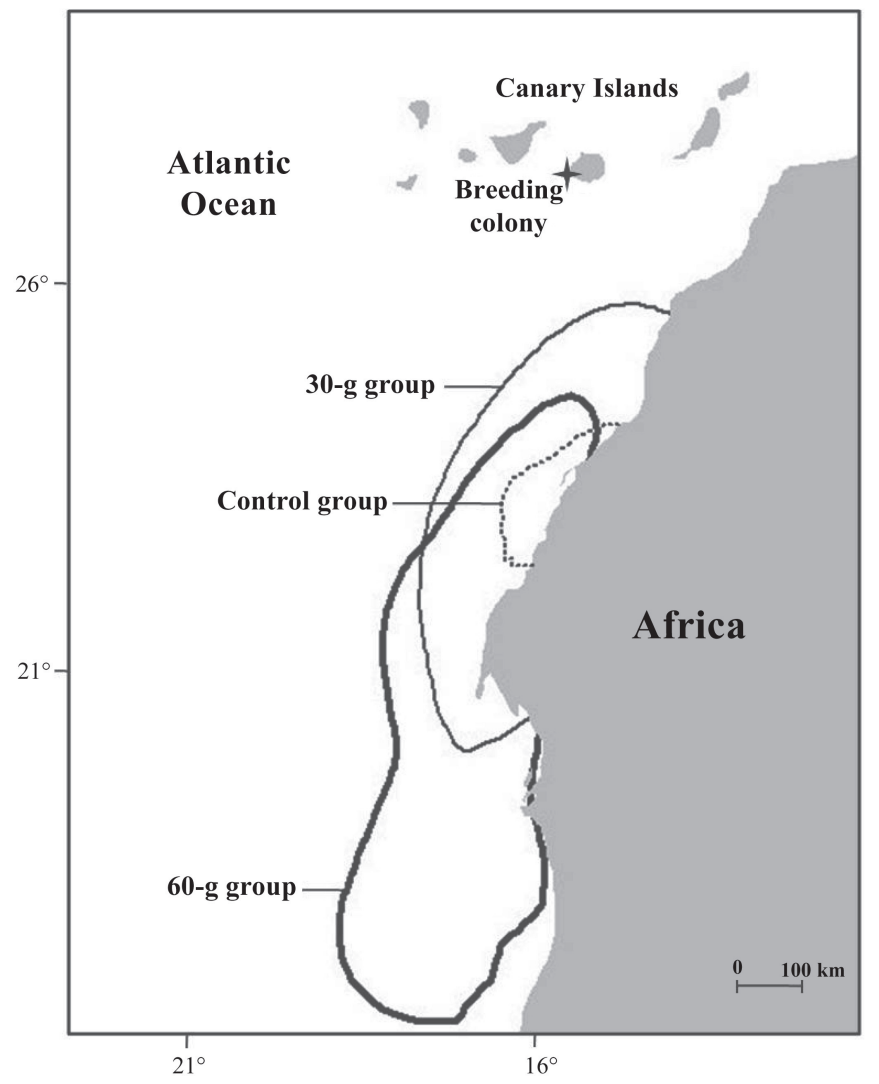

FIG. 1. Location of principal foraging areas of Cory's Shearwaters, defined as the area encompassing $50 \%$ of filtered positions, for control, 30 -g, and 60-g groups (see text). 
$\pm 49.3 \mathrm{~g}[\mathrm{SD}] ; n=50)$. The weights were covered with plastic tape (total size: $40 \times 20 \times 5 \mathrm{~mm}$ ) and differed only in their mass. They were attached with 6 to 10 mid-dorsal feathers of the mantle using 3 strips of tape (Tesa Tape, Charlotte, North Carolina) following typical techniques for attaching satellite transmitters to seabirds (Wilson and Wilson 1989). We arranged each bird's contour feathers so that the load was covered to minimize drag in the air and under water. After one foraging trip we removed the loads from all birds.

To track foraging trips, all birds were equipped with geolocators (British Antarctic Survey, Cambridge, United Kingdom). These miniaturized recording devices $(16 \times 14 \times 6 \mathrm{~mm}, 2.5 \mathrm{~g})$ were mounted on a Darvic ring and attached on the right leg. The geolocators have a photoreceptor that measures light levels every $60 \mathrm{~s}$, and they record the maximum reading within each 10 -min interval with reference to an internal clock-calendar. Sunset and sunrise times were estimated from thresholds in light curves; latitude was derived from day (or night) duration and longitude from the time of local midday (or midnight) with respect to Greenwich Mean Time and day of the year, providing 2 locations day ${ }^{-1}$ (one corresponding to midday and the other to midnight). The instrument also has a conductivity sensor that checks for immersion in salt water every $3 \mathrm{~s}$. Readings are summarized as the number of readings in salt water over each 10-min interval. Thereby, the instrument can be used to estimate the time spent at sea surface (salt-water periods) against the time spent flying (dry periods) (Afanasyev 2004). To compute the percentage of time spent on the sea surface over a foraging trip, we assumed the first and last immersion at sea to be the onset and end of the foraging trip, respectively (González-Solís et al. 2002).

\section{Variables and Statistical Analyses}

We used both indirect and direct measures to study the effect of extra mass on foraging behavior.

Indirect measures.-We measured the duration of the foraging trip, the net mass gained at sea (body mass at return - body mass at departure), the relative mass gained (net mass gained $x$ $100 /$ mass at departure), and the foraging efficiency as the rate of daily mass gained while foraging (net mass gained / duration of the foraging trip). For birds that were not weighed on the day of departure $(n=21)$, we estimated the mass at departure using the last mass recorded and the proportional daily loss of mass (mean daily mass loss $=15.8 \mathrm{~g}$ day $^{-1}$, calculated for 27 incubating birds that were weighed more than once).

Direct measures.-Data on the positions of birds tracked by geolocators were obtained and postprocessed according to the methods described by BirdLife International (2004). The accuracy of the light-level geolocation is relatively low (average error $\sim 200 \mathrm{~km}$; Phillips et al. 2004, Shaffer et al. 2005). However, the aim of our study was not a detailed description of the foraging grounds but a comparison of the foraging behavior between weighted and control birds. Any obtained position (in a short period, as in the present study) is under the same accuracy error, and to avoid potential selection biases of locations we applied a homogeneous filter based solely on a velocity index (i.e., we did not discard positions just because they were on land, although it is well known that shearwaters never go to land for foraging; see below). In this context, the low accuracy of geolocation could only contribute to obscure any differences in foraging behavior among control and weighted birds.

To filter unrealistic positions, we removed those with a velocity index $\left(V_{\mathrm{i}}\right)$ above $50 \mathrm{~km} \mathrm{~h}^{-1}$ (Navarro and González-Solís 2007), indicating an unlikely movement out and back from the normal track as defined by the preceding and following position. The velocity index was calculated as the root mean square of the velocity of the segments between the 2 preceding and the 2 following positions (see McConnell et al. 1992). By this procedure, we discarded from the analysis $2 \%$ of 556 total positions. The mean flight speed was estimated by averaging the flight speed between filtered positions. The distance traveled was calculated as the sum of distances between filtered positions, and we measured the maximum distance flown from the colony (maximum foraging range). We defined the main foraging area at 3 different levels as the areas encompassing 50\%, 75\%, and 95\% of filtered positions using the kernel analysis. From the records of immersion in salt water, we analyzed both the daily rhythm of activity and the percentage of time spent on the sea surface during the entire foraging trip.

To evaluate the treatment effect on each variable, one-way analyses of variance (ANOVAs) and least-significant-difference post hoc comparisons were used. We used natural log transformation to normalize the main-foraging-area and maximumforaging-range variables. Differences were considered significant when $P<0.05$. We used SPSS, version 14.0 for Windows (SPSS, Chicago, Illinois), and the Animal Movement Extension for ARCVIEW, version 3.2 (Hooge and Eichenlaub 1997), to perform statistical and kernel analyses, respectively.

\section{Results}

Five weighted birds did not return to their nests (3 in the 60 -g group and 2 in the 30 -g group), possibly as a consequence of the experimental manipulation. In 4 other cases (3 in the 60-g group and 1 control), the nests were deserted early by the males, resulting in loss of the egg. Thus, 27 of 36 birds were recaptured at the end of the foraging trip (control, $n=11 ; 30$-g, $n=10 ; 60$-g, $n=6$ ).

Indirect measures: Duration of foraging trip and changes in body mass.-We found significant differences among groups in the duration of the foraging trip, net mass gained, relative mass gained, and foraging efficiency. Foraging-trip duration was significantly greater for both the weighted groups than for the control group (Table 1). Both net and relative mass gained at sea differed significantly among the 3 groups (Table 1 ). The mass gained was significantly greater for the control group than for the 30 -g group and was significantly greater for the latter than for the 60 -g group (Table 1). Foraging efficiency was significantly lower for both weighted groups than for the control group (Table 1).

Direct measures: Foraging-trip movements and activity.Geolocator positions were located along the northern Atlantic coast of Africa, mainly on the coast of Western Sahara and Mauritania (Fig. 1). Mean flight speed did not differ among the 3 groups (Table 1). Distance traveled was $41 \%$ and $35 \%$ greater for the 30 -g and 60 -g groups, respectively, than for the control group, although these values did not differ significantly (Table 1). Nevertheless, when all weighted birds were pooled to form a single weighted group, the differences were significant $(F=5.37$, 
TABLE 1. Comparative analysis of pelagic behavior of 3 groups of Cory's Shearwaters: a control group, a group carrying 30-g weights, and a group carrying 60 -g weights. Values are means $\pm \mathrm{SD}$, with sample size in parentheses.

\begin{tabular}{|c|c|c|c|c|c|c|}
\hline Parameter & Control group & 30-g group & 60-g group & $F$ & df & $P$ \\
\hline \multicolumn{7}{|l|}{ Indirect measures: } \\
\hline $\begin{array}{l}\text { Duration of foraging } \\
\text { trip (days) }\end{array}$ & $9.92 \pm 1.26(11)$ & $11.70 \pm 2.26(10)$ & $13.00 \pm 2.00(6)$ & 6.59 & 2 and 26 & $<0.01$ \\
\hline Net mass gained (g) & $156.44 \pm 31.41(11)$ & $97.88 \pm 38.69(10)$ & $58.63 \pm 30.02(6)$ & 17.57 & 2 and 26 & $<0.01$ \\
\hline Relative mass gained (\%) & $24.62 \pm 5.58$ & $14.98 \pm 6.42(10)$ & $8.78 \pm 4.86(6)$ & 16.15 & 2 and 26 & $<0.01$ \\
\hline $\begin{array}{l}\text { Foraging efficiency } \\
\qquad\left(\mathrm{g} \mathrm{day}^{-1}\right)\end{array}$ & $15.79 \pm 4.09$ & $8.57 \pm 3.83(10)$ & $4.57 \pm 2.45(6)$ & 20.22 & 2 and 26 & $<0.01$ \\
\hline \multicolumn{7}{|l|}{ Direct measures: } \\
\hline Flight speed $\left(\mathrm{km} \mathrm{h}^{-1}\right)$ & $16.20 \pm 3.09(10)$ & $16.66 \pm 4.42(10)$ & $15.48 \pm 6.82(6)$ & 0.12 & 2 and 25 & 0.89 \\
\hline $\begin{array}{l}\text { Distance traveled } \\
\qquad\left(10^{3} \mathrm{~km}\right)\end{array}$ & $3.88 \pm 1.02(10)$ & $5.48 \pm 1.58(10)$ & $5.24 \pm 2.48(6)$ & 2.62 & 2 and 25 & 0.09 \\
\hline $\begin{array}{l}\text { Distance traveled per } \\
\text { day }(\mathrm{km})\end{array}$ & $388.9 \pm 74.1(10)$ & $452.1 \pm 117.5$ & $393.0 \pm 151.8(6)$ & 0.93 & 2 and 25 & 0.40 \\
\hline $\begin{array}{l}\text { Maximum foraging } \\
\text { flown }\left(10^{3} \mathrm{~km}\right)\end{array}$ & $0.99 \pm 0.25(10)$ & $1.45 \pm 0.36(10)$ & $1.42 \pm 0.77(6)$ & 4.04 & 2 and 25 & 0.03 \\
\hline \multicolumn{7}{|c|}{ Main foraging area $\left(10^{3} \mathrm{~km}^{2}\right)$} \\
\hline $50 \%$ & $67.19 \pm 51.84(10)$ & $134.59 \pm 93.66(10)$ & $180.34 \pm 239.57(6)$ & 3.32 & 2 and 25 & 0.05 \\
\hline $75 \%$ & $178.46 \pm 119.58(10)$ & $335.90 \pm 205.18(10)$ & $434.07 \pm 603.46(6)$ & 2.59 & 2 and 25 & 0.10 \\
\hline $95 \%$ & $395.21 \pm 184.28(10)$ & $754.89 \pm 349.49(10)$ & $917.24 \pm 1008.12(6)$ & 3.90 & 2 and 25 & 0.04 \\
\hline \multicolumn{7}{|c|}{ Time spent on sea surface $(\%)$} \\
\hline Totality of foraging trip & $52.01 \pm 7.23(11)$ & $54.80 \pm 6.41(10)$ & $56.14 \pm 3.97(6)$ & 0.93 & 2 and 26 & 0.41 \\
\hline In daytime & $42.67 \pm 8.10(11)$ & $40.72 \pm 8.49(10)$ & $40.47 \pm 6.45(6)$ & 0.22 & 2 and 26 & 0.81 \\
\hline At night & $67.99 \pm 13.79(11)$ & $78.37 \pm 7.30(10)$ & $82.28 \pm 4.95(6)$ & 4.66 & 2 and 26 & 0.02 \\
\hline
\end{tabular}

$\mathrm{df}=1$ and $25, P=0.03)$. Distance traveled per day did not differ among the 3 groups (Table 1). Maximum distance flown from the breeding colony was $46 \%$ and $43 \%$ greater for the 30 -g and 60 -g groups, respectively, than for the control group, and significant differences were found between the control and 30-g groups (Table 1). Main foraging area encompassing 95\% of locations was greater for both the weighted groups than for the control group, although values differed significantly only between the control and 30-g groups (Table 1). For the others levels, although both the weighted groups showed an apparent increase of the foraging area, values did not differ significantly among groups (Table 1). However, when all weighted birds were again pooled, the differences turned out to be significant at all main-foraging-area levels (50\%: $F=6.91, \mathrm{df}=1$ and 25, $P=0.02 ; 75 \%: F=5.23, \mathrm{df}=1$ and 25 , $P=0.03$; 95\%: $F=8.08, \mathrm{df}=1$ and $25, P=0.01)$.
Differences in foraging descriptors among groups could result from differences in trip duration among control and weighted groups. Therefore, to control for differences in trip duration among groups, we again compared foraging descriptors but considered only the first 8 days of each foraging trip (the minimum trip duration in all birds included in the study; Table 2). Distance traveled was $14 \%$ and $19 \%$ greater for the 30 -g and 60 -g groups, respectively, than for the control group, although values did not differ significantly (Table 2). Maximum distance flown from the breeding colony was significantly greater for both the weighted groups than for the control group (Table 2). Main foraging areas encompassing $50 \%, 75 \%$, and $95 \%$ of locations were greater for both the weighted groups than for the control group, although values did not differ significantly among groups (Table 2). Nevertheless, when all weighted birds were pooled, differences turned out to be significant

TABLE 2. Comparative analysis of foraging-trip parameters (for the first 8 days of the trip) for 3 groups of Cory's Shearwaters: a control group, a group carrying 30 -g weights, and a group carrying 60 -g weights. Values are means \pm SD, with sample size in parentheses.

\begin{tabular}{|c|c|c|c|c|c|c|}
\hline Parameter & Control group & 30-g group & 60 -g group & $F$ & $\mathrm{df}$ & $P$ \\
\hline $\begin{array}{l}\text { Distance traveled } \\
\quad\left(10^{3} \mathrm{~km}\right)\end{array}$ & $2.81 \pm 0.55$ & $3.19 \pm 1.00(10)$ & $3.33 \pm 1.49(6)$ & 0.63 & 2 and 25 & 0.54 \\
\hline $\begin{array}{l}\text { Maximum foraging } \\
\text { flown }\left(10^{3} \mathrm{~km}\right)\end{array}$ & $0.98 \pm 0.26(10)$ & $1.38 \pm 0.37(10)$ & $1.42 \pm 0.77(6)$ & 3.55 & 2 and 25 & 0.04 \\
\hline \multicolumn{7}{|c|}{ Main foraging area $\left(10^{3} \mathrm{~km}^{2}\right)$} \\
\hline $50 \%$ & $59.51 \pm 31.81(10)$ & $117.37 \pm 66.44(10)$ & $141.70 \pm 191.17(6)$ & 2.37 & 2 and 25 & 0.11 \\
\hline $75 \%$ & $174.33 \pm 98.05$ & $308.74 \pm 173.26(10)$ & $391.20 \pm 583.32(6)$ & 1.63 & & 0.22 \\
\hline $95 \%$ & $397.50 \pm 196.70(10)$ & $711.73 \pm 395.88(10)$ & $923.50 \pm 1251.90(6)$ & 1.88 & 2 and 25 & 0.17 \\
\hline
\end{tabular}




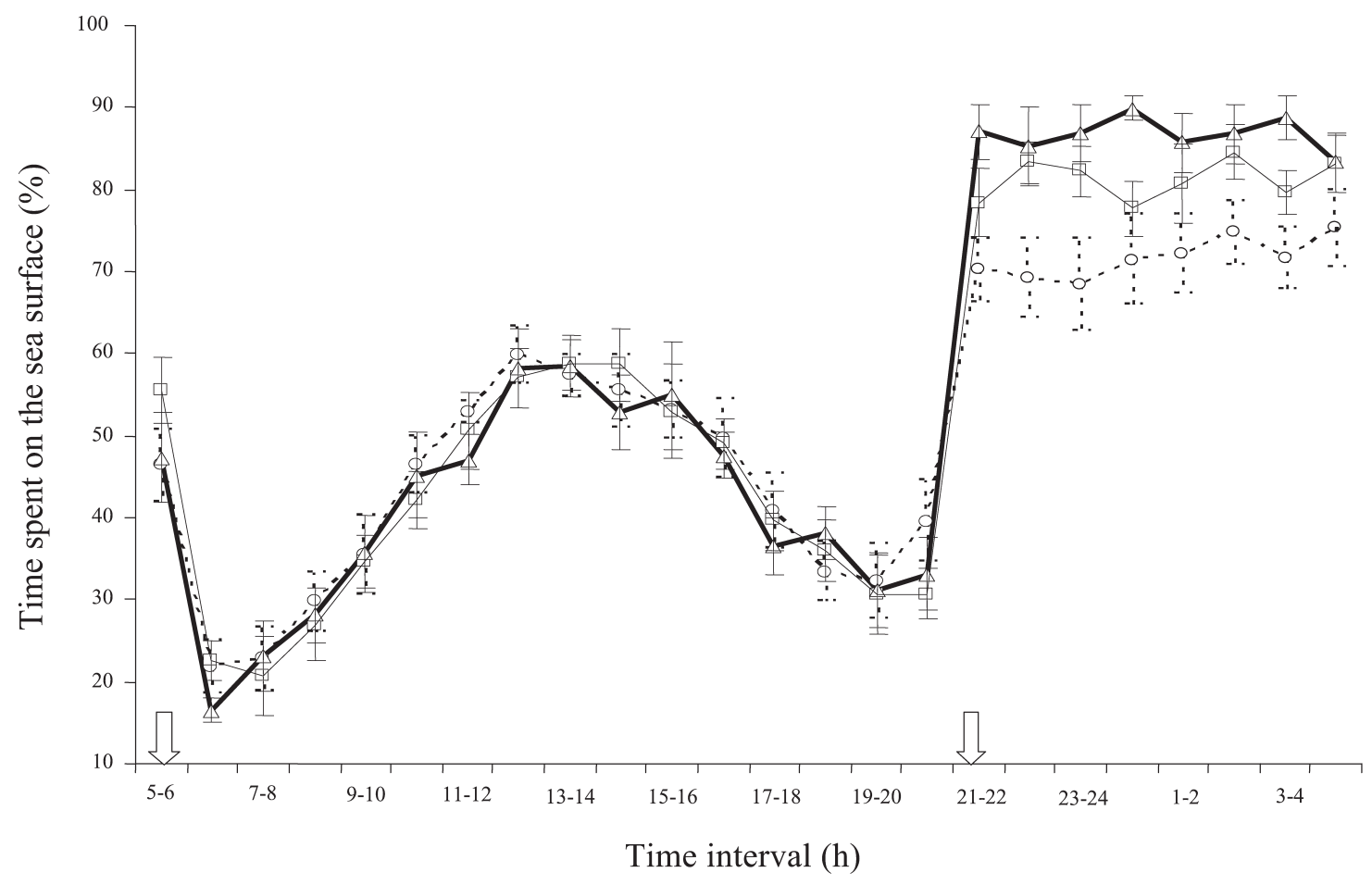

FIG. 2. Time that weighted and control Cory's Shearwaters spent on the sea surface at different times of day during a foraging trip. Thick line $=60$-g group $(n=6)$, fine line $=30$-g group $(n=10)$, and dashed line $=$ control group $(n=11)$. Arrows indicate sunrise and sunset. Values are means \pm SE.

for foraging areas encompassing $50 \%$ of locations $(F=4.53, \mathrm{df}=1$ and $25, P=0.04)$ and marginally nonsignificant for those encompassing $95 \%$ of locations $(F=3.78, \mathrm{df}=1$ and $25, P=0.06)$.

The percentage of time spent on the sea surface during the entire foraging trip did not differ significantly among groups but was slightly higher for the weighted groups (Table 1). All groups showed the same daily rhythm of activity. Birds spent more time on the sea surface during the night hours and showed a consistent increase in time spent on the sea surface during the central hours of the day (Fig. 2). The mean percentage of time spent on the sea surface in daytime (from sunrise to sunset) did not differ significantly among groups (Table 1). However, the mean percentage of time spent on the sea surface at night (from sunset to sunrise) was significantly greater for both the weighted groups than for the control group (Table 1). The difference among groups was evident from the beginning of each foraging trip (Fig. 3).

\section{Discussion}

Weighted Cory's Shearwaters increased their trip duration substantially, which is similar to results from several other seabirds species (Tveraa et al. 1997, Duriez et al. 2000, Weimerskirch et al. 2000 b, Navarro et al. 2008). The weighted groups showed a decrease in foraging efficiency, which was more noticeable when the load was heavier; this suggests that the extra mass significantly altered foraging ability. Weighted birds did not gain as much mass as control birds by the end of the trip, which indicates that longer trip duration did not completely compensate for the decline in foraging efficiency.
In addition, we detected noticeable changes in the pelagic behavior of weighted birds. Search effort was greater in weighted than in control birds: weighted birds increased the distance they traveled and their maximum foraging range and expanded their foraging area (Table 1). These effects were not merely a result of weighted birds foraging on more days than control birds: the same tendencies appeared when we compared foraging descriptors of

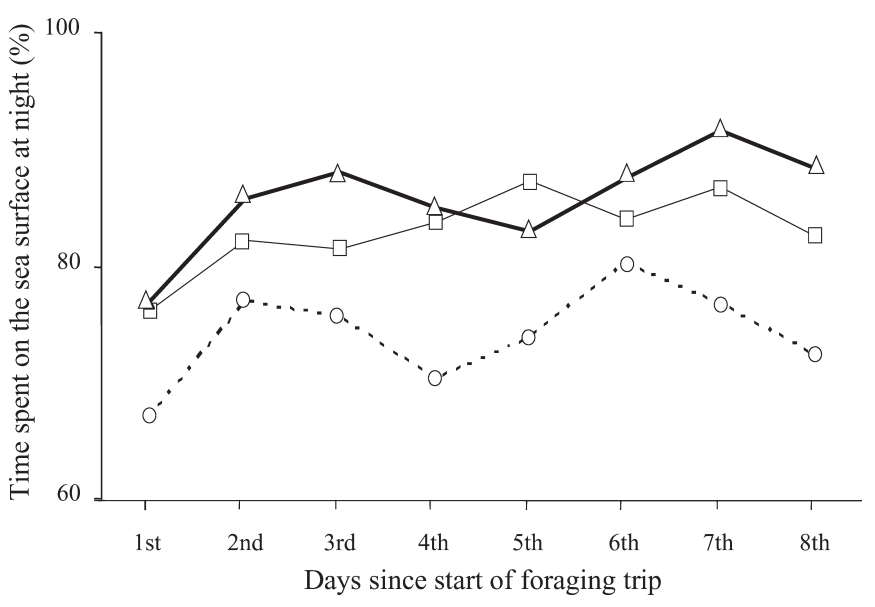

FIG. 3. Time that weighted and control Cory's Shearwaters spent on the sea surface at night (from sunset to sunrise) during the first 8 days of a foraging trip. Thick line $=60-\mathrm{g}$ group $(n=6)$, fine line $=30$-g group $(n=10)$, and dashed line $=$ control group $(n=11)$. 
weighted and control birds truncated after 8 days (Table 2). However, in spite of the differences in search effort, both control and weighted birds foraged on the African continental shelf off the coast of Western Sahara and Mauritania. This area is one of the main upwelling zones of the Atlantic Ocean, with high biological productivity and high food availability for seabirds (Barton et al. 1998, Davenport et al. 2002). The birds' mean flight speed did not seem to be affected by the extra mass they carried. There is evidence that shearwaters travel with prevailing winds (Shaffer et al. 2006, González-Solís et al. 2007, Navarro and González-Solís 2009), thereby saving much energy during the flight (Weimerskirch et al. 2000a). In a study on the foraging behavior and energetics of Wandering Albatrosses (Diomedea exulans), Arnould et al. (1996) did not find a significant relationship between energy expenditure and the proportion of time spent flying, distance flown, or average speed, which suggests that time spent in flight is not the most important determinant of energy use during foraging trips.

Furthermore, we also found effects of the extra mass on activity patterns. All birds presented the same daily rhythm of activity, flying more during the day than at night. This general pattern has been widely documented in several seabirds (Mougin and Jouanin 1997, González-Solís et al. 2002, Weimerskirch and Guionnet 2002). In our study, however, the time spent on the sea surface at night was significantly greater for the weighted groups than for the control group. Weighted birds may have needed to spend more time on the water at night because they were more tired and needed more rest than control birds. Alternatively, this may reflect differences in foraging strategies between control and weighted birds (search flights vs. sit-and-wait; Weimerskirch et al. 1997). The diet of Cory's Shearwaters includes fish and numerous species of mesopelagic squid (Granadeiro et al. 1998). Some of these species undertake vertical migrations, ascending to the surface only at night (Imber 1973, Prince and Morgan 1987). As a result of vertical migration, the density of prey is very high; thus, mobility is not necessary for feeding, and the sit-and-wait strategy may become more profitable at night (Weimerskirch et al.1997, Phalan et al. 2007). Flight, on the other hand, is associated with an extensive search for dispersed prey at sea. We hypothesize that weighted birds, whose foraging abilities appeared to be diminished, mainly took advantage of night provisioning, whereby displacement was not necessary and the prey were easily accessible. Therefore, differences in time spent at the sea surface at night may be attributable to greater exploitation of the vertical migration of squid by weighted birds. However, although sit-and-wait behavior is probably less energetically expensive than search flights at night, it is likely a less successful strategy than daytime search flights (Catry et al. 2004), and this is probably why weighted birds showed a decrease in foraging efficiency in spite of the previous observation.

In summary, our study showed a broad array of effects of an experimental increase in foraging cost on the foraging behavior of Cory's Shearwaters. Among all parameters analyzed, values differed significantly between the 30 -g and 60 -g groups only in mass gained at sea. This result may be attributable to the small sample size of the 60 -g group. Weighted birds had decreased foraging efficiency and returned to the breeding colony with lower mass gain than control birds. The lower body mass found in weighted birds may compensate for the wing-loading increase imposed by the extra mass. That is, it may be an adaptive response to reduce their flight cost by reducing their body mass (Norberg 1981). However, the lower mass may be a cost imposed by decreased hunting abilities and, thus, decreased access to food. In support of this, changes in foraging strategies of weighted birds included increased duration of foraging trips and increased search effort. Weighted birds traveled greater distances, covered a greater foraging area, and increased the maximum foraging range compared with control birds. In addition, they spent more time on the sea surface at night, when the sit-and-wait strategy may become more profitable and the prey are easily accessible.

Our results underline the need to quantify the effects of monitoring equipment, such as satellite transmitters and GPS devices, that are commonly used to study the pelagic behavior of seabirds. Given the evidence for extended trip duration and increased search effort, it is essential for any analysis of habitat preferences and foraging ranges to determine whether the tracks of tagged birds were representative. We suggest that geolocators can be used to control the effects of heavier instruments on foragingtrip movements and activity patterns.

\section{ACKNOWLEDGMENTS}

We thank P. Calabuig and Cabildo de Gran Canaria for logistical support, two anonymous reviewers for helpful comments on the manuscript, and G. Passos for improving the English. Financial support was provided by the projects CGL2006-01315/BOS, from Ministerio de Ciencia e Innovacion and fondos FEDER, and BIOCON04/099, from Fundación Banco Bilbao Vizcaya Argentaria. All methods used in this study complied with the laws of Spain.

\section{Literature Cited}

Afanasyev, V. 2004. A miniature daylight level and activity data recorder for tracking animals over long periods. Memoirs of the National Institute of Polar Research, Special Issue 58:227-233.

Arnould, J. P. Y., D. R. Briggs, J. P. Croxall, P. A. Prince, AND A. G. Wood. 1996. The foraging behaviour and energetics of Wandering Albatrosses brooding chicks. Antarctic Science 8:229-236.

Ballard, G., D. G. Ainley, C. A. Ribic, and K. R. Barton. 2001. Effect of instrument attachment and other factors on foraging trip duration and nesting success of Adélie Penguins. Condor 103:481-490.

Barton, E. D., J. Arístegui, P. Tett, M. Cantón, J. GarcíaBraun, S. Hernández-León, L. Nykjaer, C. Almeida, J. Almunia, S. Ballesteros, AND others. 1998. The transition zone of the Canary Current upwelling region. Progress in Oceanography 41:455-504.

BirdLife International. 2004. Tracking Ocean Wanderers: The Global Distribution of Albatrosses and Petrels. Results from the Global Procellariiform Tracking Workshop, 1-5 September, 2003, Gordon's Bay, South Africa. BirdLife International, Cambridge, United Kingdom.

Burger, A. E., And S. A. Shaffer. 2008. Application of tracking and data-logging technology in research and conservation of seabirds. Auk 125:253-264. 
Catry, P., R. A. Phillips, B. Phalan, J. R. D. Silk, and J. P. CroxALL. 2004. Foraging strategies of Grey-headed Albatrosses Thalassarche chrysostoma: Integration of movements, activity and feeding events. Marine Ecology Progress Series 280:261-273.

Davenport, R., S. Neuer, P. Helmke, J. Perez-Marrero, and O. Llinas. 2002. Primary productivity in the northern Canary Islands region as inferred from SeaWiFS imagery. Deep Sea Research, Part II 49:3481-3496.

Duriez, O., H. WeimerskirCh, ANd H. Fritz. 2000. Regulation of chick provisioning in the Thin-billed Prion: An interannual comparison and manipulation of parents. Canadian Journal of Zoology 78:1275-1283.

Gómez-Díaz, E., J. GonzÁlez-Solís, And M. A. Peinado. 2009. Population structure in a highly pelagic seabird, the Cory's Shearwater Calonectris diomedea: An examination of genetics, morphology and ecology. Marine Ecology Progress Series 382: 197-209.

GonzÁlez-Solís, J., J. P. Croxall, And D. R. Briggs. 2002. Activity patterns of Giant Petrels, Macronectes spp., using different foraging strategies. Marine Biology 140:197-204.

GonzÁlez-Solís, J., J. P. Croxall, D. Oro, And X. Ruiz. 2007. Trans-equatorial migration and mixing in the wintering areas of a pelagic seabird. Frontiers in Ecology and the Environment 5:297-301.

Granadeiro, J. P., L. R. Monteiro, and R. W. Furness. 1998. Diet and feeding ecology of Cory's Shearwater Calonectris diomedea in the Azores, north-east Atlantic. Marine Ecology Progress Series 166:267-276.

Hamer, K. C., R. A. Phillips, S. Wanless, M. P. Harris, AND A. G. Wood. 2000. Foraging ranges, diets and feeding location of gannets Morus bassanus in the North Sea: Evidence from satellite telemetry. Marine Ecology Progress Series 200:257-264.

Hill, R. D. 1994. Theory of geolocation by light levels. Pages 227236 in Elephant Seals: Population Ecology, Behavior, and Physiology (B. J. Le Boeuf and R. M. Laws, Eds.). University of California Press, Berkeley.

Hooge, P. N., AND B. Eichenlaub. 1997. Animal movement extension to ArcView, version 1.1. Alaska Biological Science Center, U.S. Geological Survey, Anchorage.

Hyrenbach, K. D., P. Fernández, and D. J. Anderson. 2002. Oceanographic habitats of two sympatric North Pacific albatrosses during the breeding season. Marine Ecology Progress Series 233:283-301.

Imber, M. J. 1973. The food of Grey-faced Petrels (Pterodroma macroptera gouldi Hutton), with special reference to diurnal vertical migration of their prey. Journal of Animal Ecology 42:645-662.

Magalhães, M. C., R. S. Santos, And K. C. Hamer. 2008. Dualforaging of Cory's Shearwaters in the Azores: Feeding locations, behaviour at sea and implications for food provisioning of chicks. Marine Ecology Progress Series 359:283-293.

McConnell, B. J., C. Chambers, and M. A. Fedak. 1992. Foraging ecology of southern elephant seals in relation to the bathymetry and productivity of the Southern Ocean. Antarctic Science 4:393-398.

Mougin, J.-L., And C. Jounnin. 1997. Foraging zone of the Cory's Shearwater Calonectris diomedea borealis of Selvagem Grande $\left(30^{\circ} 09^{\prime} \mathrm{N}, 15^{\circ} 52^{\prime} \mathrm{W}\right)$ during incubation, using satellite telemetry. Comptes rendus de l'Academie des sciences Series III 320:825-831.

Navarro, J., And J. GonzÁlez-Solís. 2007. Experimental increase of flying costs in a pelagic seabird: Effects on foraging strategies, nutritional state and chick condition. Oecologia 151: $150-160$.

Navarro, J., AND J. GonzÁLEZ-Solís. 2009. Environmental determinants of foraging strategies in Cory's Shearwaters Calonectris diomedea. Marine Ecology Progress Series 378:259-267.

Navarro, J., J. González-Solís, G. Viscor, and O. Chastel. 2008. Ecophysiological response to an experimental increase of wing loading in a pelagic seabird. Journal of Experimental Marine Biology and Ecology 358:14-19.

NorberG, R. A. 1981. Temporary weight decrease in breeding birds may result in more fledged young. American Naturalist 118:838850.

Paredes, P., I. L. Jones, AND D. J. Boness. 2005. Reduced parental care, compensatory behaviour and reproductive costs of Thickbilled Murres equipped with data loggers. Animal Behaviour 69:197-208.

Phalan, B., R. A. Phillips, J. R. D. Silk, V. Afanasyev, A. Fukuda, J. Fox, P. Catry, H. Higuchi, and J. P. Croxall. 2007. Foraging behaviour of four albatross species by night and day. Marine Ecology Progress Series 340:271-286.

Phillips, R. A., J. R. D. Silk, J. P. Croxall, V. Afanasyev, And D. R. BRIGgs. 2004. Accuracy of geolocation estimates for flying seabirds. Marine Ecology Progress Series 266:265-272.

Phillips, R. A., J. C. Xavier, And J. P. Croxall. 2003. Effects of satellite transmitters on albatrosses and petrels. Auk 120:10821090.

Prince, P. A., And R. A. Morgan. 1987. Diet and feeding ecology of Procellariifomes. Pages 135-171 in Seabirds: Their Feeding Ecology and Role in Marine Ecosystems (J. P. Croxall, Ed.). Cambridge University Press, Cambridge, United Kingdom.

Shaffer, S. A., Y. Tremblay, J. A. Awkerman, R. W. Henry, S. L. H. Teo, D. J. Anderson, D. A. Croll, B. A. Block, And D. P. CostA. 2005. Comparison of light- and SST-based geolocation with satellite telemetry in free-ranging albatrosses. Marine Biology 147:833-843.

Shaffer, S. A., Y. Tremblay, H. Weimerskirch, D. Scott, D. R. Thompson, P. M. Sagar, H. Moller, G. A. Taylor, D. G. Foley, B. A. Block, AND D. P. CostA. 2006. Migratory shearwaters integrate oceanic resources across the Pacific Ocean in an endless summer. Proceedings of the National Academy of Sciences USA 103:12799-12802.

SöHLE, I. S. 2003. Effects of satellite telemetry on Sooty Shearwater, Puffinus griseus, adults and chicks. Emu 103:373-379.

Thibault, J.-C., V. Bretagnolle, and C. Rabouam. 1997. Calonectris diomedea Cory's Shearwater. Birds of the Western Palearctic Update 12:75-98.

TveraA, T., S.-H. Lorentsen, And B.-E. SÆther. 1997. Regulation of foraging trips and costs of incubation shifts in the Antarctic Petrel (Thalassoica antarctica). Behavioral Ecology 8:465-469.

Weimerskirch, H., A. Catard, P. A. Prince, Y. Cherel, and J. P. Croxall. 1999. Foraging White-chinned Petrels Procellaria aequinoctialis at risk: From the tropics to Antarctica. Biological Conservation 87:273-275. 
WeimerskirCh, H., AND T. Guionnet. 2002. Comparative activity pattern during foraging of four albatross species. Ibis 144:40-50.

Weimerskirch, H., T. Guionnet, J. Martin, S. A. Shaffer, and D. P. Costa. 2000a. Fast and fuel efficient? Optimal use of wind by flying albatrosses. Proceedings of the Royal Society of London, Series B 267:1869-1874.

Weimerskirch, H., M. Le Corre, S. Jaquemet, and F. MarSAC. 2005. Foraging strategy of a tropical seabird, the Red-footed Booby, in a dynamic marine environment. Marine Ecology Progress Series 288:251-261.

Weimerskirch, H., P. A. Prince, and L. Zimmermann. 2000b. Chick provisioning by the Yellow-nosed Albatross Diomedea chlororhynchos: Response of foraging effort to experimentally increased costs and demands. Ibis 142:103-110.
Weimerskirch, H., R. P. Wilson, And P. Lys. 1997. Activity pattern of foraging in the Wandering Albatross: A marine predator with two modes of prey searching. Marine Ecology Progress Series 151:245-254.

Wilson, R. P., AND M.-P. Wilson. 1989. Tape: A packageattachment technique for penguins. Wildlife Society Bulletin $17: 77-79$

Xavier, J. C., P. N. Trathan, J. P. Croxall, A. G. Wood, G. Podestá, AND P. G. Rodhouse. 2004. Foraging ecology and interactions with fisheries of Wandering Albatrosses (Diomedea exulans) breeding at South Georgia. Fisheries Oceanography 13:324-344.

Associate Editor: D. C. Dearborn 